2020-09

\title{
Awareness of bone health risks in people with epilepsy and intellectual disability
}

\section{Sawhney, I}

http://hdl.handle.net/10026.1/17180

\subsection{1/bld.12321}

British Journal of Learning Disabilities

Wiley

All content in PEARL is protected by copyright law. Author manuscripts are made available in accordance with publisher policies. Please cite only the published version using the details provided on the item record or document. In the absence of an open licence (e.g. Creative Commons), permissions for further reuse of content should be sought from the publisher or author. 
See discussions, stats, and author profiles for this publication at: https://www.researchgate.net/publication/339311348

\section{Awareness of bone health risks in people with epilepsy and intellectual disability}

Article in British Journal of Learning Disabilities · February 2020

DOI: $10.1111 /$ bld.12321

CITATIONS

4 authors, including:

Inder Sawhney

Hertforshire Partnership Univeristy Foundation NHS trust

11 PUBLICATIONS 37 CITATIONS

SEE PROFILE

Rohit Shankar

University of Plymouth

191 PUBLICATIONS 944 CITATIONS

SEE PROFILE
READS

26

Asif Zia

Hertfordshire Partnership NHS Foundation Trust

19 PUBLICATIONS 90 CITATIONS

SEE PROFILE

Some of the authors of this publication are also working on these related projects:

ID-AED - A Register for Collecting and Measuring Outcomes of licensed AEDs in patients with Epilepsy and Intellectual Disability and/or Pervasive Developmental Disorders View project

Epilepsy technology View project 


\title{
Awareness of bone health risks in people with epilepsy and intellectual disability
}

\author{
Indermeet Sawhney $^{1}$ | Asif Zia ${ }^{1}$ | Bahar Yazdi ${ }^{1}$ | Rohit Shankar ${ }^{2,3}$ (D)
}

${ }^{1}$ Hertfordshire Partnership University NHS Foundation Trust, Essex, UK

${ }^{2}$ Cornwall Partnership NHS Foundation Trust, Truro, UK

${ }^{3}$ University of Exeter Medical School, Exeter, UK

\section{Correspondence}

Rohit Shankar, Cornwall Partnership Foundation NHS Trust, Chy Govenek, Threemilestone industrial estate, Truro TR4 9LD, UK.

Email: rohit.shankar@nhs.net

\section{Accessible Summary}

- There are worries about the impact of epilepsy and antiepilepsy drugs (AEDs) on bone health and the increased risk of fractures.

- It is now considered important that people with epilepsy should be told about the long-term effects of AEDs particularly risk of fractures.

- People with intellectual disability are more prone to have seizures which do not respond fully to AEDs, on multiple AEDs and thus higher risk of fractures.

- This is a small study to see whether people with intellectual disability and/or their carers are informed of the risks of AEDs and fractures including how to reduce them.

- The study found that there is little evidence of people with intellectual disability and epilepsy and/or their carers being informed in spite of their increased risks.

\section{Abstract}

Background: People with epilepsy (PWE) have a higher fracture risk than nonepilepsy populations. Antiepileptic drugs (AEDs) cause bone loss. Limited physical activity and poor dietary intake increase fracture risk in PWE. People with an intellectual disability have higher prevalence of epilepsy, likely to be on multiple AEDs, with poorer response, thus at a higher risk of sustaining fractures compared to general population. Ignorance of these issues can add to the risk. The study ascertains bone health knowledge in people with epilepsy and their carers.

Materials and Methods: A literature search on intellectual disability, epilepsy, bone health and patient knowledge informed a codesign survey with a service user group. An easy read survey version was created. It was disseminated via NHS Trust clinicians to all service users and their carers receiving services from a specialist learning disability team (catchment population-1,000,000).

Results: Thirty-four carers and 23 service users of total 148 eligible (response rate $38.5 \%)$ responded to the questionnaires disseminated by clinicians. Approximately $50 \%$ of carers and $25 \%$ of people with epilepsy had awareness of the increased fracture risk. Less than $25 \%$ of the respondents associated AEDs to bone loss. Less than a third were aware of protective strategies to reduce fracture risk.

Conclusions: The survey showed significant knowledge shortcomings of both service user and carer groups of relationship between intellectual disability, epilepsy, its medications, fracture risk, and available risk reduction strategies. Clinicians need 
to be proactive in providing service users and carers with information around bone health and epilepsy.

KEYWORDS

antiepileptic drugs, bone health, epilepsy, fracture, intellectual disability, learning disability

\section{1 | INTRODUCTION}

Prevalence of epilepsy in people with intellectual disability or learning disability is reported to be at least 20 times greater than those with epilepsy from the general population (Amiet et al., 2008; Branford, Bhaumik, \& Duncan, 1998). Approximately $22.5 \%$ of people with intellectual disability have epilepsy (Robertson, Hatton, Emerson, \& Baines, 2015) of whom $68 \%$ are suggested to be pharmaco resistant (McGrother et al., 2006). The Confidential Inquiry into Premature Deaths of People with Learning Disabilities (Heslop et al., 2013) showed $43 \%$ of people had epilepsy with antiepileptic drugs (AEDs) being the most commonly associated medication. Refractory epilepsy can be progressive with long-term risks. Risks associated with AEDs such as osteoporosis can get neglected (Laxer et al., 2014).

The downside of AEDs, particularly their adverse metabolic effects on the bone, has received scant attention, due to these concerns remaining subclinical for a considerable period of time after initiation (Arora, Singh, \& Gupta, 2016). Studies have demonstrated that PWE have risk of increased metabolic bone disease and fracture than nonepilepsy populations (Elliott, Seals, \& Jacobson, 2008). Up to one third of this increased risk is reported to be due to injuries acquired at the time of seizures (Sheik Ahmad et al., 2012) possibly predisposed by bone changes. AEDs cause bone loss (Elliott et al., 2008), compounded by maladaptive lifestyle highlighted by limited physical activities and poor dietary intakes which has been found to increase the risk of fracture in PWE (Elliott et al., 2008). Physically restricted PWE show an increase in number of fractures up to two to three times compared to otherwise healthy PWE (Souverein, Webb, Weil, Van Staa, \& Egberts, 2006). Side effects of AEDs also put PWE at risk of falls (Zaccara, Cincotta, Borgheresi, \& Balestrieri, 2004) and subsequent fractures. Bone loss can happen just after two years of AED prescribing (Elliott \& Jacobson, 2006). A cumulative association between number and duration of AED use, and fracture risk has been demonstrated (Souverein et al., 2006).

Both low bone mineral density (BMD) or bone mass and vitamin $D$ deficiency are established independent risk factors for fracture. In PWE, vitamin D deficiency is reported to be a common cause for the bone loss, secondary to use of AEDs (Elliott et al., 2008). AEDs are associated with disorders, affecting bone metabolism and density. Hypocalcaemia, hypophosphatemia, reduction in serum levels of vitamin D, increase in parathormone (PTH) levels and changes in bone turnover markers are the main metabolic effects of AEDs on the bone (Arora et al., 2016).
A person with epilepsy and intellectual disability is also likely to multimorbidity and as a result polypharmacy (Royal College of Psychiatrists CR206, 2017a; Royal College of Psychiatrists CR 203, 2017b). A recent study has suggested that an average adult with intellectual disability has approximately 11 physical health conditions, epilepsy being among the most common (Kinnear et al., 2018). In addition, there is evidence of over-representation of major mental health concerns in people with intellectual disability particularly those with epilepsy (McGrother, Thorp, Taub, \& Machando, 2001). Thus, higher levels of mental and physical health medication are prescribed to this population thus increasing likelihood of side effects including impact on bone (Royal College of Psychiatrists 206, 2017a). These would include commonly used drugs such as steroids and psychotropics. A further concern would be the protection on bone provided by oestrogen lost to women when they become menopausal thus increasing the risk of fractures especially if vulnerable to other risk factors (National Health Service, 2017).

The importance of bone health and informing patients about it is overlooked by clinicians (Elliott \& Jacobson, 2006). A survey by a UK national epilepsy charity established that $75 \%$ of their members stated never being informed about the possibility of osteoporosis and osteomalacia as a result of use of AEDs (Epilepsy Action, 2003). Similar results (75\%) were reported in another study around lack of information about AED side effects (Elliott et al., 2008).

Literature specific to intellectual disability, epilepsy and bone health are limited. An audit demonstrated not only the lack of information provided to people with intellectual disability but the need to do so in a meaningful person-centred manner (Sawhney, Adams, \& Zia, 2017). The General Medical Council (2001) considers effective and sensitive communication to be one of the "essentials of basic clinical method." However, failure of healthcare providers to communicate effectively and appropriately with people with disabilities is a major barrier to delivery of quality health care for people with disabilities. Osteoprotective knowledge related to calcium and exercise has not been assessed specifically in PWE in the intellectual disability population. With advanced age bones are more prone to fracture. Thus, the ageing intellectual disability population with epilepsy has further risk concerns. Other apprehensions include that popular osteoporosis screening tools such as Q-Fracture and FRAX have not been validated in the intellectual disability population (Redfern, Jory, \& Shankar, 2014). Small-scale studies have shown that these tools regularly show a "false negative" for people with intellectual disability thus putting this population at further risk of iatrogenic harm (Redfern et al., 2014). 
The National Institute for Health and Care Excellence (NICE, 2012) recommends that clinicians need to have clear discussions with people around AEDs including indications for prescribing AEDs as well as their adverse effects. The provided information needs to be in line with NHS England's Accessible Information Standard (2016). NICE guidelines also suggest that clinicians ought to pay careful attention to treatment-induced side effects, for instance bone health issues. This includes performing blood tests in patients on enzyme-inducing drugs (NICE, 2012). The Scottish Intercollegiate Guidelines Network (SIGN, 2015) also advises on giving dietary and other lifestyle advice to minimise the risk of osteoporosis.

\section{AIM}

How aware are people with intellectual disability and epilepsy and their carers of bone health risks and osteoporosis preventative strategies.

\section{3 | MATERIAL AND METHODS}

\subsection{Questionnaire design and ethics}

The questionnaires were codesigned and coproduced by a local group of experts with experience including service users and carers. No specific psychometric testing of validity was conducted. It was presumed to have face validity.

The study sought to invite individuals irrespective of their level of intellectual disability. Due to varying levels of intellectual disability of participants, various options to complete the questionnaire were proposed, that is independent, supported and proxy. Some service users who could themselves respond to the questionnaire, while some others might benefit from help while for substantial population their carers would need to provide information. The survey included a questionnaire in two formats. A copy of both format was made available to each participant and their carers. One format was to assess the carers' knowledge around relation between epilepsy, fracture risk and medications (Appendix 1). The other was an easy read version for service users about the same (Appendix 2). It was requested that either the service user copy or the carer copy be returned to prevent duplication. In the service user questionnaire returns, it was not possible to distinguish the level of support an individual received in completing the survey. No parameters for the proxy answers were established.

\section{2 | Settings}

Clinicians, both psychiatrists and community nurses, across a learning disability service in the south of England were asked to disseminate the questionnaires among service users with epilepsy and their carers, who were seen in outpatient clinics or home visits. The NHS Trust supports an area with a population of a million in which the expected numbers of people with intellectual disability is expected to be around 10,000 people.

\section{3 | Implementation}

Data were collected prospectively. Service users with a diagnosis of intellectual disability and epilepsy, in the NHS Foundation Trust, between August 2017 and January 2018, were included in this project.

\subsection{Data collection}

The service users and their carers' knowledge about the risks of people with epilepsy suffering from a fracture, and bone loss associated with AEDs, were assessed. Their knowledge about preventative measures was also ascertained.

\subsection{Ethics}

Data were collected as a service evaluation and registered as such with the NHS organisation. The NHS Health research authority tool (http://www.hra-decisiontools.org.uk/research/index.html) helps confirm as whether ethical approval is required for a project. A group email to all clinicians working in the service was sent requesting them for their assistance to disseminate the survey.

\section{4 | RESULTS}

The survey was disseminated by four learning disability psychiatrists and their teams to an eligible population of 148 people with intellectual disability and epilepsy. These 148 were people open to the health services at the time of survey. Thirty-four carers and 23 patients completed the questionnaires. This was a response rate of $38.5 \%$. Eighteen $(53 \%)$ of carers and six (26\%) of service users, who participated in this survey, were aware that PWE have an increased risk of suffering from a fracture. Seven (21\%) of carers and five (22\%) of service users were aware that AEDs can cause bone loss. Twenty-three (68\%) of carers and eleven (48\%) of service users were aware that bone loss can increase the risk of having a broken bone (Table 1, Figure 1). Eleven (32\%) of carers and five (22\%) of service users were aware of some strategies to reduce risk of fracture in PWE and provided their views on what they considered to be preventive of fractures (Table 2).

\section{5 | DISCUSSION}

The collected data show shortcomings in knowledge of both service user and carer groups about the relation between epilepsy and the 
TABLE 1 Results of survey questions

\begin{tabular}{lllll}
$\begin{array}{l}\text { Participants } \\
N=57\end{array}$ & $\begin{array}{l}\text { Awareness of PWE being exposed } \\
\text { to increased fracture risk }\end{array}$ & $\begin{array}{l}\text { Knowledge of AEDs } \\
\text { causing bone loss }\end{array}$ & $\begin{array}{l}\text { Understanding of bone loss } \\
\text { increasing the fracture risk }\end{array}$ & $\begin{array}{l}\text { Awareness of risk } \\
\text { reduction strategies }\end{array}$ \\
\hline Carers $n=34$ & $18(53 \%)$ & $7(21 \%)$ & $23(68 \%)$ & $11(32 \%)$ \\
Service users $n=23$ & $6(26 \%)$ & $5(22 \%)$ & $11(48 \%)$ & $5(22 \%)$ \\
\hline
\end{tabular}

Abbreviations: AED, antiepilepsy drugs; PWE, people with epilepsy.

Awareness of risk reduction

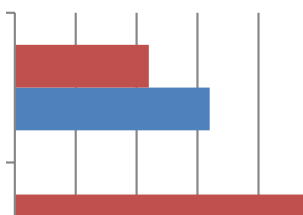

Bone loss increasing the fracutre risk

AEDs causing bone loss

PWE increased risk of fractures

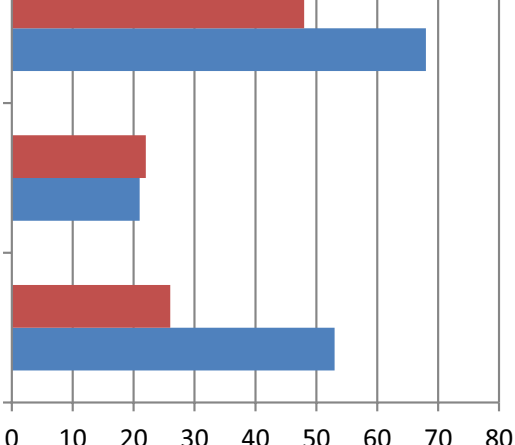

FIGURE 1 Results of knowledge of relationship of bone health and epilepsy (\%) n service users

ncarers risk of fracture, and also their knowledge of risk reduction. Lack of knowledge in our sample is established not only by the low numbers of carers and service users who responded to awareness of strategies for prevention but also by those who replied (Table 2). In those who replied there was clear inconsistency in response. Other than for three carers each suggesting calcium supplements or dairy products most answers were incongruous thus highlighting the further need for structured education.

The Health Belief Model (HBF; Figure 2) is a useful template to structure the problem and help identify solutions to provide education. HBF is a social psychological health behaviour change model developed to explain and predict health-related behaviours, particularly in regard to the uptake of health services. HBF suggests that patients are unlikely to comply with preventative measures if they perceive a condition as not severe and if they view their risk of developing a condition as low (Elliott \& Jacobson, 2006). Hence, service users and carers knowledge of the relation between epilepsy and bone health can play an important part in reducing risk of fracture in people with epilepsy. This is particularly relevant as in seizure management the focus can be on the seizure control and long-term issues such as impact on bone can get neglected. Those with intellectual disability are at particular risk.

Clinicians need to be more proactive in terms of providing the service users and carers with information around relation between bone health and epilepsy highlighting the perceived threats. This information can include explanation about the relationship between antiepileptic medications and bone health and also advice about healthy lifestyle choices. Additionally developing leaflets in the form of easy read is of crucial importance in improving the knowledge of service users about this. This is to overcome the communication difficulties and illiteracy levels among people with intellectual

TABLE 2 Comments provided by carers and service users on their perception of what could make fractures less likely

\begin{tabular}{|c|c|}
\hline Carers' answers & Service users' answers \\
\hline 1. Diary products & $\begin{array}{l}\text { 1. Being careful } \\
\text { Looking where we go }\end{array}$ \\
\hline $\begin{array}{l}\text { 2. Drinking Milk. } \\
\text { Exercise. }\end{array}$ & 2. No fall \\
\hline $\begin{array}{l}\text { 3. Type of seizures. } \\
\text { Duration of seizures. }\end{array}$ & 3. Calcium tablets \\
\hline $\begin{array}{l}\text { 4. Controlling the frequency of epilepsy. } \\
\text { Monitoring and keeping the place clear of } \\
\text { obstacles. }\end{array}$ & 4. No falling over \\
\hline $\begin{array}{l}\text { 5. Turning on side. } \\
\text { Make sure no dangerous objects is near. } \\
\text { Having beds near ground or sides. }\end{array}$ & $\begin{array}{l}\text { 5. No weak bones } \\
\text { No falling }\end{array}$ \\
\hline \multicolumn{2}{|l|}{ 6. Milk } \\
\hline \multicolumn{2}{|l|}{$\begin{array}{l}\text { 7. Fall on something soft. } \\
\text { If know a seizure is coming sit down. }\end{array}$} \\
\hline \multicolumn{2}{|l|}{$\begin{array}{l}\text { 8. Calcium } \\
\text { Vitamins }\end{array}$} \\
\hline \multicolumn{2}{|l|}{ 9. Medication } \\
\hline $\begin{array}{l}\text { 10. Bone scan. } \\
\text { Vitamins and Supplements. }\end{array}$ & \\
\hline 11. Good calcium intake & \\
\hline
\end{tabular}


FIGURE 2 Health Belief Model (Glanz \& Bishop, 2010)

\section{The Health Belief Model}

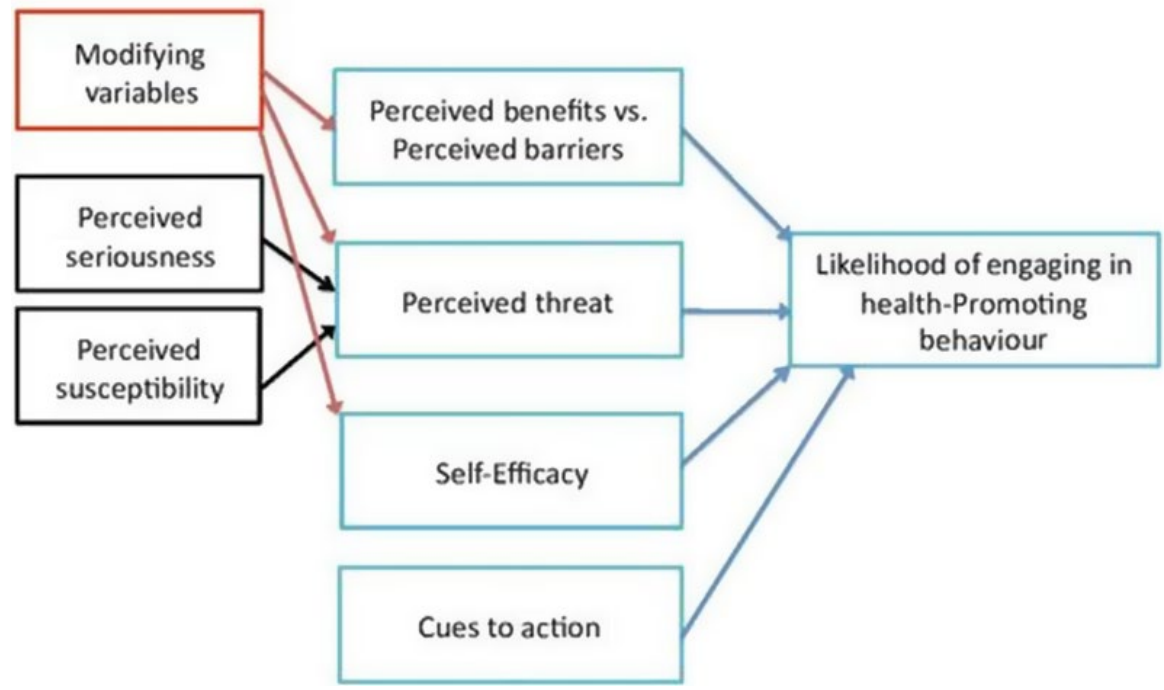

disability. The responsibility to deliver information lies with all clinicians who work regularly with people with intellectual disability and epilepsy as highlighted by NICE (NICE, 2012).

Opportunities to enquire and conduct relevant investigations around bone welfare in the vulnerable group present itself during the Annual Health Checks (National Health Service). Further oversight of this could happen via the multidisciplinary team. Particular vigilance needs to be kept over issues such as falls which is particularly common in people with chronic epilepsy (Jory, Oak, Organ, Mclean, \& Shankar, 2019).

\section{1 | Limitations}

Lack of detailed demographic data such as male/female ratio, race, age, comorbid diagnosis, number of AEDs and details of other bone health influencing medication such as psychotropics are limitations. Should this information were collected, a more in-depth analysis of the results would have been possible. Nevertheless, the focus of the survey was gaining insight to the level of knowledge in this population irrespective of the individual characteristics of the service user.

\section{6 | CONCLUSION}

Results strongly suggest poor knowledge of service users and their carers about relation between epilepsy and bone health regardless of the various potential confounders and bias. The emphasis needs to be on improving the knowledge about bone health and epilepsy in a person-centred manner.

\section{CONFLICT OF INTEREST}

None.

\section{DATA AVAILABILITY STATEMENT}

The data that support the findings of this study are available from the corresponding author upon reasonable request.

\section{ORCID}

Rohit Shankar (iD https://orcid.org/0000-0002-1183-6933

\section{REFERENCES}

Ahmad, B., Hill, K. D., O'Brien, T. J., Gorelik, A., Habib, N., \& Wark, J. D. (2012). Falls and fractures in patients chronically treated with antiepileptic drugs. Neurology, 79(2), 145-151. https://doi.org/10.1212/ WNL.0b013e31825f0466

Amiet, C., Gourfinkel-An, I., Bouzamondo, A., Tordjman, S., Baulac, M., Lechat, P., ... Cohen, D. (2008). Epilepsy in autism is associated with intellectual disability and gender: Evidence from a meta-analysis. Biological Psychiatry, 64, 577-582.

Arora, E., Singh, H., \& Gupta, Y. K. (2016). Impact of antiepileptic drugs on bone health: Need for monitoring, treatment, and prevention strategies. Journal of Family Medicine and Primary Care, 5(2), 248-253.

Branford, D., Bhaumik, S., \& Duncan, F. (1998). Epilepsy in adults with learning disabilities. Seizure, 7, 473-477.

Elliott, J. O., \& Jacobson, M. P. (2006). Bone loss in epilepsy: Barriers to prevention, diagnosis, and treatment. Epilepsy \& Behavior, 8(1), 169-175.

Elliott, J. O., Seals, B. F., \& Jacobson, M. P. (2008). Osteoprotective knowledge in a multiethnic epilepsy population. Journal of Neuroscience Nursing, 40(1), 14-24. https://doi.org/10.1097/01376517-20080 2000-00004

Epilepsy Action (2003). Anti-epileptic drugs and the risk of osteoporosis and osteomalacia: How much information do patients taking anti-epileptic drugs feel they receive about side effects of this medication? Retrieved from www.epilepsy.org.uk/research/reports/osteoporosis.html

Glanz, K., \& Bishop, D. B. (2010). The role of behavioral science theory in development and implementation of public health interventions. Annual Review of Public Health, 31, 399-418.

Heslop, P., Blair, P., Fleming, P., Houghton, M., Marriott, A., \& Russ, L. (2013). Confidential inquiry into premature deaths of people with learning disabilities (CIPOLD) final report. Retrieved from http://www.brist ol.ac.uk/cipold/fullfinalreport.pdf 
Jory, C., Oak, K., Organ, C., Mclean, B., \& Shankar, R. (2019). Head first Review of epilepsy head injury risk and protection. Seizure, 71, 66-79. https://doi.org/10.1016/j.seizure.2019.06.013

Kinnear, D., Morrison, J., Allan, L., Henderson, A., Smiley, E., \& Cooper, S. A. (2018). Prevalence of physical conditions and multimorbidity in a cohort of adults with intellectual disabilities with and without Down syndrome: Cross-sectional study. British Medical Journal Open, 8(2), e018292. https://doi.org/10.1136/bmjopen-2017-018292

Laxer, K. D., Trinka, E., Hirsch, L. J., Cendes, F., Langfitt, J., Delanty, N., ... Benbadis, S. R. (2014). The consequences of refractory epilepsy and its treatment. Epilepsy \& Behavior, 37, 59-70. https://doi. org/10.1016/j.yebeh.2014.05.031

McGrother, C. W., Bhaumik, S., Thorp, C. F., Hauck, A., Branford, D., \& Watson, J. M. (2006). Epilepsy in adults with intellectual disabilities: Prevalence, associations and service implications. Seizure, 15, 376-386.

McGrother, C., Thorp, C., Taub, N., \& Machando, O. (2001). Prevalence, disability and need in adults with severe learning disability. Tizard Learning Disability Review, 6, 4-13. https://doi.org/10.1108/13595 474200100022

National Health Service. Retrieved from https://www.england.nhs.uk/ learning-disabilities/improving-health/annual-health-checks/

National Health Service (2017). Menopause and your bone health. England, UK. Retrieved from https://www.nhs.uk/live-well/healthy-body/ menopause-and-your-bone-health/

National Institute for Health and Care Excellence (2012) Epilepsies: Diagnosis and management (CG137). London, UK: NICE.

Redfern, P., Jory, C., \& Shankar, R. (2014). Identification of osteoporosis among people with intellectual disability being treated with anti-epileptic drugs. Epilepsia, 55(supplement S2), 211.
Robertson, J., Hatton, C., Emerson, E., \& Baines, S. (2015). Prevalence of epilepsy among people with intellectual disabilities: A systematic review. Seizure, 29, 46-62. https://doi.org/10.1016/j.seizu re.2015.03.016

Royal College of Psychiatrists (2017a). College report 206. London, UK: Royal College of Psychiatrists.

Royal College of Psychiatrists (2017b). College Report 203. London, UK: Royal College of Psychiatrists.

Sawhney, I., Adams, D., \& Zia, A. (2017). Bone health and people with a learning disability who are prescribed epilepsy medication. Learning Disability Practice, 20(5), 23-27.

Scottish Intercollegiate Guidelines Network (2015). Diagnosis and management of epilepsy in adults: A national clinical guideline (SIGN143). Edinburgh, UK: SIGN.

Souverein, P. C., Webb, D. J., Weil, J. G., Van Staa, T. P., \& Egberts, A. C. (2006). Use of antiepileptic drugs and risk of fractures: Case-control study among patients with epilepsy. Neurology, 66(9), 1318-1324. https://doi.org/10.1212/01.wnl.0000210503.89488.88

Zaccara, G., Cincotta, M., Borgheresi, A., \& Balestrieri, F. (2004). Adverse motor effects induced by antiepileptic drugs. Epileptic Disorders, 6(3), 153-168.

How to cite this article: Sawhney I, Zia A, Yazdi B, Shankar R.

Awareness of bone health risks in people with epilepsy and intellectual disability. Br J Learn Disabil. 2020;00:1-8. https:// doi.org/10.1111/bld.12321 


\section{APPENDIX 1}

SAMPLE OF SURVEY TOOL, USED TO ASSESS THE SERVICE USERS' KNOWLEDGE ABOUT BONE HEALTH AND EPILEPSY

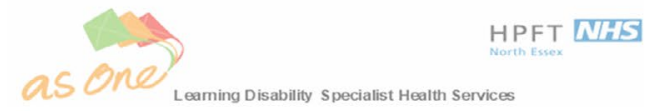

Dear Service user

We would like to see what you know about the chance (risk) of having a broken bone (fracture) in people with fits (epilepsy). We would also like to see if you know how to make this less likely. You can help us by completing this survey. Please tick the box that applies to you.

Thank you very much for your help.

1. Are people with fits (epilepsy) more likely to break their bones?

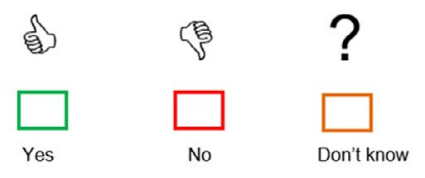

2. Can medications, that are used to treat fits (Epilepsy) weaken the bones?

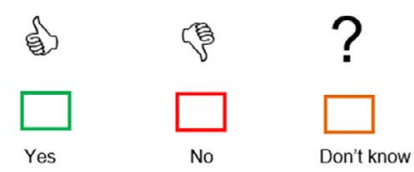

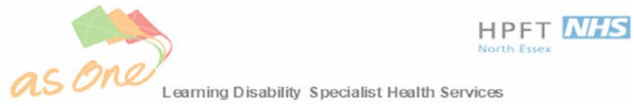

3. Do weakened bones make it more likely that you get a broken bone (fracture)?

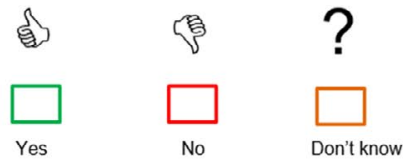

4. Can you name two things that make it less likely that you get a broken bone (fracture)?

$1-$

5. Is there anything else that you would like to say?

Please do not put your name on this survey.

The information from the survey forms may be shared.

Thank you very much for taking part. 
APPENDIX 2

SAMPLE OF SURVEY TOOL, USED TO ASSESS THE CARERS' KNOWLEDGE ABOUT BONE HEALTH AND EPILEPSY

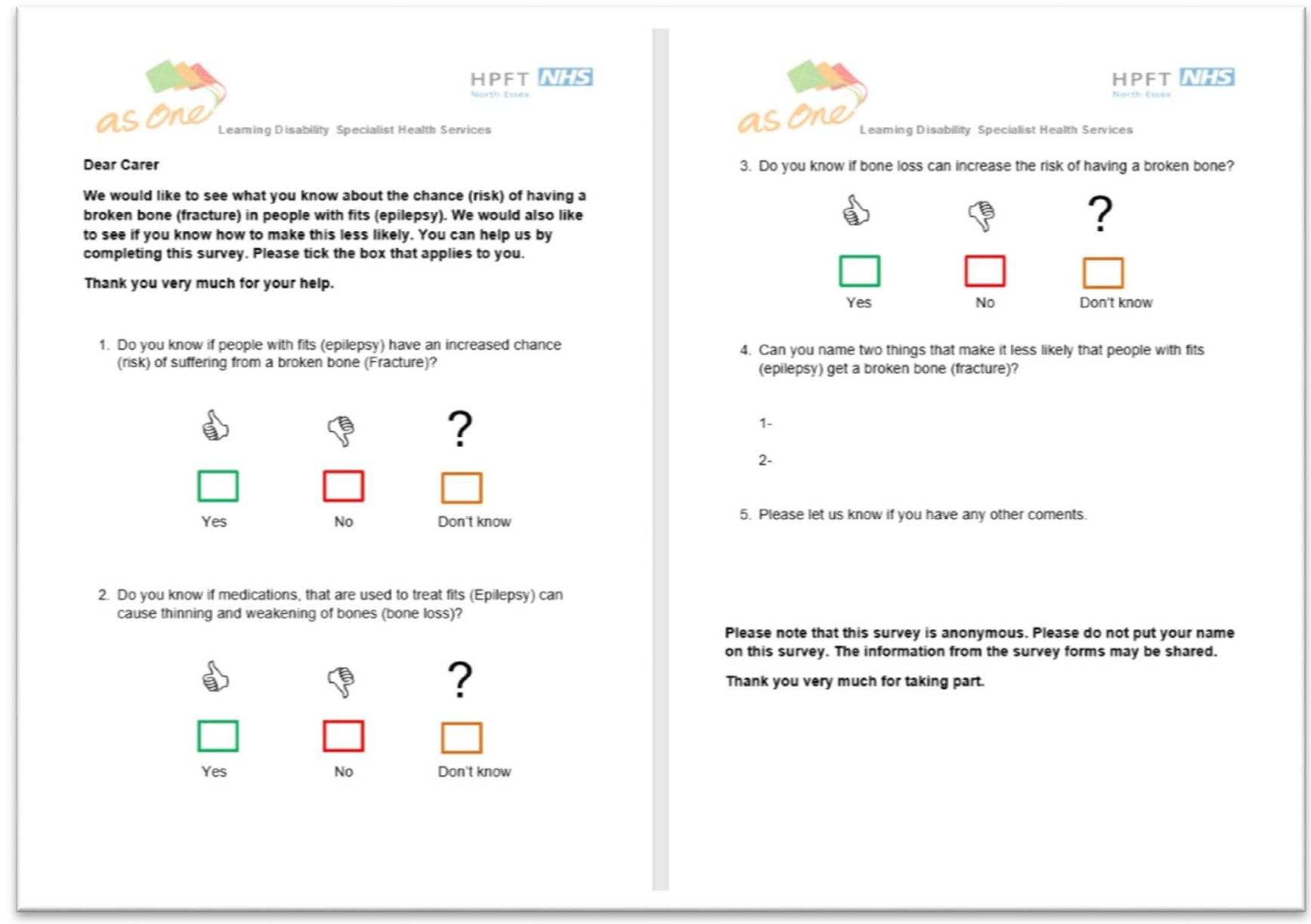

